\title{
BIOMONITORAMENTO ATIVO DE METAIS TRAÇO E EFEITO BIOLÓGICO EM MEXILHÕES TRANSPLANTADOS PARA ÁREA DE INFLUÊNCIA DE EFLUENTE DE INDÚSTRIA DE BENEFICIAMENTO DE AÇO - FASE I
}

\author{
BELLOTTO, V.R. ; DE BRITO, P.C. ; MANZONI, G. \& WEGNER, E. \\ CTTMar/UNIVALI - CX.P. 360, Itajaí, SC - CEP 88302-202 \\ bellotto@univali.br
}

\begin{abstract}
Bellotto, V.R. ; de Brito, P.C. ; Manzoni, G. \& Wegner, E. 2005. Biomonitoring of trace metals and biological effects in introduced mussels related to an industrial plant effluent submarine outflow - Phase I. Braz. J. Aquat. Sci. Technol. 9(2):33-37. ISSN 1808-7035. Preliminary results from an environmental monitoring program of an industrial submarine outflow are presented. Introduced mussels technique with Perna perna was applied. Two evaluations were carried out; one thirty days after the transplant and, another one, sixty days after the first one. Trace metal bioaccumulation and the associated cellular damage were determined. In the first evaluation, in the beginning of the industrial activity, concentrations significantly higher of some metals in mussels of the area of the emissary in comparison with the control site had been registered. In the second evaluation higher concentrations were recorded only for $\mathrm{Cd}, \mathrm{Zn}$ and $\mathrm{Ni}$ at submarine outflow zone. Despite this, the recorded concentrations remained in the range considered normal for the studied species and below of the maximum level accepted by law for human consumption. The Neutral Red Assay, the biomarker applied, evidenced no cellular damage.
\end{abstract}

Keywords: Trace Metals, Mussels, Biomonitoring

\section{INTRODUÇÃO}

Para avaliação da evolução temporal da bioacumulação de metais e das respostas biológicas a ela associada, em uma área de descarga de efluente de uma Planta industrial de beneficiamento de aço, foi aplicada a técnica, já bastante difundida, de transplante (Trefry et al., 1995; Bellotto, 2000), com mexilhões da espécie Perna perna. Os moluscos bivalves, entre eles os mexilhões, são reconhecidamente os melhores biomonitores em ambientes aquáticos e utilizados em programas nacionais e internacionais de monitoramento ambiental.

Estes biomonitores podem ser usados para determinar variações espaciais e/ou temporais na biodisponibilidade de metais pesados no ambiente marinho, oferecendo medidas das frações da carga total de metais no ambiente que são relevantes do ponto de vista ecotoxicológico (Bellotto, 2000). Combinado a isto, os biomarcadores de efeito têm sido utilizados com muito sucesso em situações de exposição subletal, como instrumento de uma advertência prévia de estresse induzido por poluentes. A grande vantagem desses métodos é sua sensibilidade a baixos níveis de contaminação no ambiente, subsidiando tomadas de decisões, em tempo hábil, no intuito de remediar situações de risco, antes que as mesmas alcancem níveis irreversíveis (Wedderburn et al., 2000).
Dentre os biomarcadores, a análise da estabilidade da membrana lisossômica (teste do tempo de retenção do vermelho neutro) em mexilhões, selecionada para aplicação neste trabalho, têm sido intensamente aplicada em monitoramentos de áreas costeiras sob influência de indústrias. Este teste evidencia os efeitos adversos, sofridos pelos indivíduos expostos aos componentes disponíveis, através de danos fisiológicos mensuráveis, sendo, portanto, útil na avaliação de estresse ambiental.

\section{MATERIAL E MÉTODOS}

\section{Área de estudo}

O emissário submarino da Planta Industrial está localizado na face sudeste da Ilha de São Francisco (SC) a $600 \mathrm{~m}$ da costa, conforme ilustra a figura 1.

\section{Transplante de mexilhões}

Mexilhões da espécie Perna perna com comprimento médio de $4 \mathrm{~cm}$, foram coletados no parque experimental de maricultura da Enseada de Armação de Itapocoroy, SC, considerada como área controle para o presente estudo. Em seguida, um lote de 100 indivíduos foi separado, colocado em uma lanterna, usada 


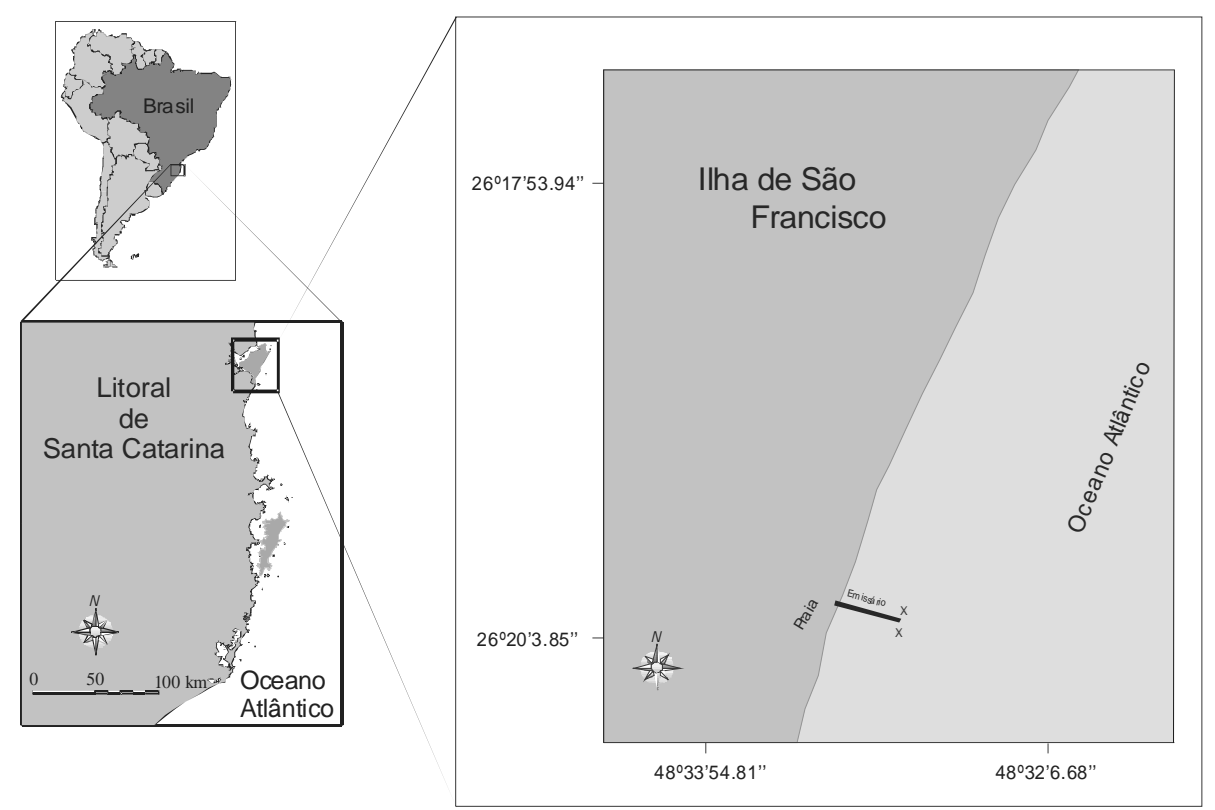

Figura 1 - Localização da área de estudo e posição do emissário submarino.

comumente para cultivo de ostra, e reintroduzido na água, na área controle. Os indivíduos restantes foram colocados em duas lanternas, as quais foram colocadas a uma profundidade média de 7 metros, que correspondia a metade da altura da coluna d'água, sendo uma a 50 metros ao sul e outra a 50 metros ao norte do emissário. Esta distância foi definida através de estudo prévio sobre a dispersão do efluente, que determinou ser este o raio do campo próximo de influência do emissário (Carvalho, 2002). O transplante foi realizado em 27 de junho de 2003, antes início das operações fabris. As coletas dos organismos transplantados ocorreram na fase inicial das atividades fabris, considerada aqui como FASE 1 do programa de monitoramento.

Coleta, procedimentos de análises e tratamento de dados

Em 30 de julho e 02 de outubro de 2003 foram coletados lotes de 20 mexilhões, de cada lanterna, para a análise química e teste com biomarcador (Teste do Vermelho Neutro), cujos procedimentos são descritos a seguir.

\section{Teste do Vermelho Neutro (biomarcador de efeito)}

O teste de retenção do vermelho neutro utilizado neste estudo foi desenvolvido a partir dos procedimentos descritos por Lowe \& Pipe (1994). Extraía-se a hemolinfa do músculo adutor posterior com ajuda de uma seringa hipodérmica, contendo $0,1 \mathrm{ml}$ solução sa- lina $(\mathrm{pH} 7,4) .50 \mu \mathrm{l}$ da suspensão de células eram depositados em uma lâmina histológica. A lâmina permanecia 15 minutos em uma câmara úmida e escura para a aderência das células. Em seguida, retirava-se o excesso da suspensão e adicionavam-se $50 \mu \mathrm{l}$ do corante Vermelho Neutro. Após 15 minutos iniciava-se a observação das lâminas. Foram observados o tempo de retenção do corante Vermelho Neutro nos compartimentos lisossômicos e as anormalidades celulares (tamanho e forma), através da microscopia óptica (x 400), em intervalos de tempo regulares. O tempo era registrado apenas no momento em que mais de $50 \%$ das células na lâmina apresentavam deformidades e efluxo do corante para o citosol.

Os dados foram registrados como tempo de retenção do vermelho neutro, aos quais foram aplicados testes estatísticos apropriados: Kruskal-Wallis-ANOVA e Dunnett a posteriori para verificação da existência e significância de diferença no tempo de retenção médio entre a área de estudo e a controle (Zar, 1984).

\section{Determinação de metais}

Após a realização dos testes do Vermelho Neutro o tecido mole de cada mexilhão foi seco em estufa, macerado e digerido em uma mistura de ácido nítrico (suprapur ${ }^{\circledR}$ Merck) e peróxido de hidrogênio (suprapur ${ }^{\circledR}$ Merck) em bloco digestor à $100^{\circ} \mathrm{C}$.

A determinação quantitativa dos metais foi realizada por Espectrometria de Massa com Plasma Inductivamente Acoplado (ICP-MS), com equipamento da marca Perkin Elmer modelo Elan 6100. A exatidão e 
repetitividade do método foram avaliadas através do uso de material de referência certificado (tecido de ostra 1566b NIST) em triplicata para cada bateria de digestão de amostra.

\section{RESULTADOS E DISCUSSÃO}

Para a campanha de julho de 2003 foram registrados valores significativamente mais elevados $(p<0,05)$ de quase todos os metais para os mexilhões coletados na área do emissário, tanto ao norte quanto ao sul, quando comparados ao controle. A exceção foi o cromo, que só apresentou concentração significativamente mais elevada $(p<0,05)$ que o controle ao norte.

Na campanha realizada em outubro de 2003, entretanto, foram verificadas diferenças significativas apenas entre as concentrações de metais dos mexiIhões coletados ao norte do emissário em relação ao controle. Para cromo e ferro, não foram evidenciadas diferenças significativas $(p>0,05)$ entre os mexilhões da área controle e aqueles coletados na zona de influência do emissário.

Os resultados encontrados para zinco são semelhantes aos relatados por Furley e Oliveira Filho (2000) em experimento semelhante feito na zona marinha sob influência da Indústria Aracruz Celulose e da mesma forma que lá, são valores considerados normais e estão dentro dos limites permitidos por lei para consumo humano de frutos do mar (Tabela 1).

No caso do ferro, se comparado aos resultados encontrados pelos autores supracitados, as concentrações encontradas neste estudo são bastante inferiores as registradas na área daquele trabalho na costa do estado do Espírito Santo. Para cádmio, entretanto,

Tabela 1 - Concentrações médias de metais ( $\mathrm{mg} / \mathrm{kg}$ de peso seco) e desvios padrões (desv.pad) em mexilhões de área controle e transplantados para a zona de influência direta do emissário submarino, para os períodos de julho e outubro de 2003. Destacadas em itálico estão as médias de concentração, expressas em peso úmido, para fins de comparação com os limites máximos permitidos (LMT) para consumo humano pela legislação brasileira (Decreto nº 55871, de 26/03/1965).

\begin{tabular}{|c|c|c|c|c|c|c|c|c|c|}
\hline \multirow[t]{2}{*}{ Data } & \multirow[t]{2}{*}{ Local } & \multirow[t]{2}{*}{ parâmetro } & $\mathbf{C u}$ & $\mathrm{Cr}$ & Cd & Zn & $\mathrm{Ni}$ & Sn & $\mathbf{F e}$ \\
\hline & & & \multicolumn{7}{|c|}{$(\mathrm{mg} / \mathrm{kg})(\mathrm{mg} / \mathrm{kg})(\mathrm{mg} / \mathrm{kg})(\mathrm{mg} / \mathrm{kg})$} \\
\hline \multirow[t]{3}{*}{$30 / 7 / 2003$} & Controle & média & 5,57 & 0,72 & 0,79 & 95,85 & 7,92 & 0,33 & 67,60 \\
\hline & & desv.pad & 1,23 & 0,12 & 0,20 & 18,40 & 2,26 & 0,06 & 14,78 \\
\hline & & média p.úmido & 0,84 & 0,11 & 0,12 & 14,38 & 1,19 & 0,05 & 10,14 \\
\hline \multirow[t]{3}{*}{$30 / 7 / 2003$} & Norte & média & 7,07 & 0,94 & 1,39 & 126,90 & 12,08 & 0,46 & 114,24 \\
\hline & & desv.pad & 1,07 & 0,22 & 0,20 & 21,88 & 3,90 & 0,14 & 19,44 \\
\hline & & média p.úmido & 1,06 & 0,14 & 0,21 & 19,03 & 1,81 & 0,07 & 17,14 \\
\hline \multirow[t]{3}{*}{$30 / 7 / 2003$} & Sul & média & 6,94 & 0,86 & 1,31 & 125,33 & 16,44 & 0,37 & 109,68 \\
\hline & & desv.pad & 2,51 & 0,24 & 0,48 & 45,17 & 5,94 & 0,07 & 43,60 \\
\hline & & média p.úmido & 1,04 & 0,13 & 0,20 & 18,80 & 2,47 & 0,06 & 16,45 \\
\hline \multirow[t]{3}{*}{$2 / 10 / 2003$} & Controle & média & 6,99 & 1,03 & 1,11 & 148,91 & 8,48 & 0,27 & 190,44 \\
\hline & & desv.pad & 2,20 & 0,56 & 0,43 & 42,35 & 3,14 & 0,08 & 59,13 \\
\hline & & média p.úmido & 1,05 & 0,15 & 0,17 & 22,34 & 1,27 & 0,04 & 28,57 \\
\hline \multirow[t]{3}{*}{ 2/10/2003 } & Norte & média & 12,14 & 1,47 & 1,68 & 221,13 & 12,45 & 0,50 & 196,84 \\
\hline & & desv.pad & 6,79 & 0,81 & 0,70 & 101,49 & 5,95 & 0,32 & 82,38 \\
\hline & & média p.úmido & 1,82 & 0,22 & 0,25 & 33,17 & 1,87 & 0,08 & 29,53 \\
\hline \multirow[t]{4}{*}{ 2/10/2003 } & Sul & média & 7,84 & 0,96 & 1,22 & 177,90 & 10,61 & 0,34 & 220,74 \\
\hline & & desv.pad & 2,71 & 0,34 & 0,44 & 59,07 & 4,88 & 0,11 & 186,30 \\
\hline & & média p.úmido & 1,18 & 0,14 & 0,18 & 26,69 & 1,59 & 0,05 & 33,11 \\
\hline & & LMT (p.úmido) & 30 & $\mathbf{0 , 1}$ & 1,0 & 50 & 5,0 & 250 & \\
\hline
\end{tabular}


as concentrações encontradas neste trabalho foram superiores àquelas reportadas por Furley \& Oliveira FiIho (2000), considerando a área de referência do trabaIho destes autores, onde as concentrações de $\mathrm{Cd}$ nos mexilhões variaram de 0,1 a 0,85 mg/kg.

Da mesma forma, quando comparados com resultados encontrados por outros autores em diferentes regiões naturais e/ou levemente impactadas por metais e áreas contaminadas por metais (Tabela 2), podese considerar que as concentrações encontradas neste estudo, para todos os metais investigados nos mexilhões Perna perna, transplantados para a zona do emissário submarino da Planta Industrial da Vega do Sul estão dentro dos padrões de ambientes naturais.

Comparando-se, ainda, as concentrações médias de metais nos mexilhões transplantados, bem como naqueles da área controle, com o limite máximo de tolerância para contaminantes inorgânicos em alimento para consumo humano (Tabela 1), segundo a legislação vigente, constata-se que, com exceção do cromo, os demais metais estão bem abaixo do limite máximo permitido.

No caso do cromo, não só no presente estudo, mas em diversos outros já realizados foi constatado que as concentrações deste metal em moluscos bivalves, mesmo em áreas isentas de qualquer tipo de poluição, são geralmente superiores aos limites máximos toleráveis. Ferreira et al. (2000) destacam esta questão, ressaltando que "medidas equivocadas de restrição do consumo de certas espécies importantes na dieta alimentar da população podem ser eventualmente tomadas" e consideram que "uma nova revisão destes índices se faz necessária, de preferência seguindose critérios internacionais de quantificação, por meio de testes de toxicidade".

O cromo é um metal que apresenta um dos maiores fatores de acumulação em moluscos bivalves como o Perna perna (Bellotto, 2000), fazendo com que pequenas concentrações no ambiente possam resultar em elevados níveis de acumulação no organismo.
Avaliação da integridade da membrana lisossômica (Teste do Vermelho Neutro)

Moluscos de áreas potencialmente impactadas apresentam um menor tempo de retenção do vermelho neutro pelos compartimentos lisossômicos e levam menos tempo para apresentar anormalidades em suas células, devido à redução da estabilidade da membrana lisossomal, quando comparados com moluscos oriundos de áreas limpas (Nascimento et al., 2002).

Na campanha de 30 de julho, verificou-se que os mexilhões da área controle levaram 78,8 minutos em média para demonstrar estresse, enquanto os mexiIhões da área de estudo, coletados ao norte e ao sul do emissário levaram em média, respectivamente 66 e 93 minutos para demonstrar estresse. A análise estatística evidenciou diferença significativa $(p<0,05)$ entre a área norte e sul do emissário; não havendo, porém, diferença significativa destas com relação ao controle, indicando que as condições dos organismos na área de estudo podem ser consideradas normais, até aquele momento.

Para os mexilhões coletados em 02 de outubro de 2003, não se verificou diferença significativa $(p<0,05)$ no tempo de retenção do Vermelho Neutro entre a área de influência do emissário submarino e o controle; indicando mais uma vez, não haver efeito negativo do lançamento do efluente industrial sobre os mexilhões na área de estudo.

\section{CONCLUSÃO}

Os resultados obtidos até o momento indicam que não está ocorrendo acumulação significativa de metais pela biota, indicando que a disponibilidade de metais no meio não está sendo ampliada pela atividade da planta industrial e a pequena elevação dos níveis de metais nos mexilhões não resultou em efeitos danosos aos organismos.

Tabela 2 - Concentrações médias de metais, expressas em $\mathrm{mg} / \mathrm{kg}$ de peso seco, em mexilhões da espécie Perna perna coletados em áreas classificadas como naturais e/ou sob baixo impacto de contaminação por metais $(\mathrm{N} . \mathrm{I}=1)$ e contaminadas por metais $(\mathrm{N} . \mathrm{I}=2)$

\begin{tabular}{ccccccccl}
\hline Local & N.I. & Cu & Cr & Cd & Zn & Ni & Fe & \multicolumn{1}{c}{ Referência } \\
\hline Baia de Guanabara & 2 & 14,5 & & & 565,5 & 19 & 171,5 & Rezende e Lacerda (1986) \\
Baia de Sepetiba & 2 & 6,5 & & 1,0 & 205,3 & 7,4 & & Carvalho et al (1993) \\
Angra dos Reis & 1 & 8,9 & & 1,0 & 153 & 9,8 & & Carvalho et al (1993) \\
Macaé & 1 & 5,1 & 1,3 & 0,3 & 79 & 8,6 & 675 & Carvalho et al (1998) \\
Praia do Retiro/RJ & 1 & 6,0 & 1,7 & 0,3 & 40 & 12 & 1190 & Ferreira et al (2000) \\
Buena/RJ & 1 & 6,7 & 1,4 & 0,3 & 42 & 4 & 1000 & Ferreira et al (2000) \\
Barra do Furado/RJ & 1 & 5,7 & 2,5 & 0,3 & 51 & 12 & 1200 & Ferreira et al (2000) \\
Penha/SC & 1 & 10 & 2,3 & 1,3 & 128,3 & 9,3 & & Bellotto (2000) \\
Penha/SC & 1 & 6,3 & 0,87 & 0,95 & 122,4 & 8,2 & 129,0 & este estudo \\
Zona do emissário & & 8,5 & 1,1 & 1,4 & 162,8 & 12,9 & 160,4 & este estudo \\
\hline
\end{tabular}

N.I= nível de impacto 


\section{AGRADECIMENTOS}

Os autores agradecem aos estagiários do laboratório de mergulho submarino e a equipe do Parque Experimental de Maricultura da Penha pelo apoio de campo. Este trabalho foi realizado com suporte financeiro da Empresa VEGA DO SUL, dentro do programa de monitoramento ambiental da área de influência de seu emissário submarino.

\section{REFERÊNCIAS}

Bellotto, V.R. 2000. Estudo sobre a bioacumulação de metais em mexilhões Perna perna (tecido mole e conchas), empregando-se as técnicas de $\mathrm{SN}$ ICPMS e LA-ICPMS. Tese de Doutorado, Pontifícia Universidade Católica- Rio de Janeiro.

Cajaraville, M. P.; Bebianno, M. J.; Blasco, J.; Porte, C.; Sarasquete, C. \& Viarengo, A. 2000. The use of biomarkers to assess the impact of pollution in coastal environments of the Iberian Península: a practical approach. The Science of the Total Environment. 247: 295-311.

Carvalho, C.E.V.; Lacerda, L.D. \& Gomes, M. P. 1993. Metais pesados na biota bêntica da Baía de Sepetiba e Angra dos Reis, RJ. Acta Limno. Brasil. 6: 222-229.

Carvalho, C.E.V.; Cavalcante, M.P.O.; Gomes, M.P.; Faria, V.V. \& Rezende, C.E. 1998. Distribuição de metais pesados em mexilhões $P$. perna da llha de Santana (Macaé, RJ). Anais do $5^{\circ}$ Enc. Brasil. ECOTOX. Itajaí, SC, Brasil.

Carvalho, J.L.B. 2002. Modelagem do transporte dos efluentes tratados do emissário submarino da Planta Industrial da VEGA DO SUL. Relatório Técnico. UNIVALI, SC.
Ferreira, A.G.; Machado, A.L.S. \& Zalmon, I.R. 2002. Metais pesados em moluscos bivalves no litoral norte do estado do Rio de Janeiro, p. 167-182. In: Espíndola, E.L.G.; Paschoal, C.R.M.B.; Rocha, O.; Boher, M.B.C. \& Oliveira Neto, A.L. [Eds], Ecotoxicologia: Perspectivas para o Século XXI. São Carlos.

Furley, T.H. \& de Oliveira Filho, A.C. 2000. Biomonitoring of heavy metals and organo-chlorinated compounds in a pulp Mill effluent using introduced mussels. Aquatic Ecosystem Health and Management Society. 3: 499-507.

Lowe, D.M \& Pipe, R.K. 1994. Contaminant induced lysossomal membrane damage in marine mussel digestive cell: in vitro study. Aquatic Toxicology. 30: 357-365.

Nascimento, I.; Sousa, E.C.P.M. \& Nipper, M.2002. Métodos em Ecotoxicologia Marinha - Aplicações no Brasil, Editora Artes Gráficas e Indústria Ltda.

Rezende C., E. \& Lacerda, L.D. 1986. Metais pesados nos mexilhões (Perna perna L.) no litoral do Estado do Rio de Janeiro. Rev. Brasil. Biol. 46 (1): 239-247.

Trefy, J.H.; Naito, K.L.; Trocine, R.P. \& Metz, S. 1995. Distribution and bioaccumulation of heavy metals from produced water discharges to the Gulf of Mexico. Water Science and Technology. 32(2): 316.

Zar, J. H. 1984.Bioestatistical analysis, Prentice Hall Ed.

Wedderburn, J.; McFadzen, I.; Sanger, R.C.; Beesley, A. Heayh, C. ; Hornby, M. \& Lowe, D. 2000. The field application of cellular and physiological biomarkers, in mussel Mytilus edulis, in conjunction with early life stage bioassay and adult histopathology. Marine Pollution Bulletin. 40 (3): 257-267. 